\title{
The impact of therapies as monotherapy with combined therapy on novel and traditional biomarkers in patients with rheumatoid arthritis
}

Accepted: 1/9/2019

\author{
Asmaa Awni Haydar ${ }^{1 *} \quad$ Ijlal Rstam Abdullah ${ }^{1}$
}

\section{Abstract}

Background and objectives: Rheumatoid arthritis is an autoimmune and inflammatory disease that influences many tissues and organs. Inflammatory markers such as C-reactive protein, erythrocyte sedimentation rate, anti-cyclic citrullinated protein, rheumatoid factor, and $14-3-3 n$ protein have been found to play an important role in both the diagnosis and progression of rheumatoid arthritis. This study aimed to elucidate the effect of anti-rheumatoid medication, as mono- and combined therapy, on these inflammatory mediators.

Methods: A cross-sectional study was performed at Hawler Medical University, College of Pharmacy, Erbil, Iraq. Forty-two patients of both genders with rheumatoid arthritis participated in the study as group I. Forty-four age-gender matched adults (with no rheumatoid arthritis) were included as a comparison group or group II. Serum levels of biomarkers were determined by enzyme linked immune sorbent assay.

Results: There was a statistically significant $(P<0.05)$ increased level of serum anti-cyclic citrullinated peptide, 14-3-3n protein, erythrocyte sedimentation rate, C-reactive protein, and rheumatic factor levels in group I compared with group II. The serum level of the anti-cyclic citrullinated peptide significantly decreased in rheumatoid patients treated with combined therapy compared with mono remedy. However, the mean of body mass index, age, and gender of group I was non-significantly different from group II $(P>0.05)$.

Conclusion: Therapeutic regimen of mono or combined therapy played a role in changing levels of inflammatory markers. Anti-cyclic citrullinated protein significantly decreased with the combined therapy in comparison with the monotherapy regimen.

Keywords: Rheumatic arthritis; Monotherapy; Combined therapy; Anti-rheumatoid; Inflammatory markers.

\section{Introduction}

Rheumatoid arthritis is a systemic chronic autoimmune and inflammatory disease that may affect many tissues and organs, but conscience attacks flexible of (synovial) joints. ${ }^{1}$ Genetic factors contribute to the development of rheumatoid arthritis. ${ }^{2}$ Female sex is associated with an increased risk of rheumatoid arthritis three times higher than men. Rheumatoid arthritis incidence increases after the age of 25 years, with greater involvement of populations between 35 and 55 years. $^{3}$ Biomarkers such as rheumatoid factor (RF) and the anti-cyclic citrullinated peptide
(ACCPA) have been shown to predate the clinical diagnosis of rheumatoid arthritis., ${ }^{4,5}$ with the ACCPA being strongly predictive for the future development of rheumatoid arthritis. ${ }^{4} \quad$ C-reactive protein (CRP) observing a specific marker of systemic inflammation and is elevated in patients with rheumatoid arthritis. ${ }^{5}$ Currently, the ACR/ EULAR (American College of Rheumatology (ACR)/European League Against Rheumatism) 2010 criteria for the rheumatoid arthritis diagnosis use the rheumatoid factor (RF) and antibodies against cyclic citrullinated proteins ACCPA. In addition, other diagnostic biomarkers

${ }^{1}$ Department of Pharmacology, College of Medicine, Hawler Medical University, Erbil, I raq.

* Correspondence: Asma.pharma12@gmail.com 
that can help the early diagnosis of rheumatoid arthritis were identified. A meta -analysis that included 14 studies showed a non-significant difference between the antibody-mutated citrullinated vimentin (anti -MCV) and ACCPA tests for rheumatoid arthritis diagnosis consummate. 14-3-3 eta protein belongs to the family of 14-3-3 proteins that it is localized intracellularly, being externalized in the inflammatory process where it can be citrullinated. The 14-3-3 proteins act like chaperonins. ${ }^{6}$ Drug therapy for rheumatoid arthritis may involve nonsteroidal anti-inflammatory drugs (NSAIDs) and oral, intramuscular, or intra-articular corticosteroids for controlling pain and inflammation. Ideally, NSAIDs and corticosteroids are used only for short-term management. DMARDs (disease-modifying anti-rheumatic drugs) are the preferred therapy. ${ }^{7,8}$ The goals of treatment include minimization of joint pain and swelling, prevention of radiographic damage and visible deformity, and continuation of work and personal activities. ${ }^{9}$ NSAIDs represent one of the most widely used classes of drugs and are used primarily for patients who have moderate to severe symptoms or if evidence of inflammation is present, treatment of osteoarthritis, rheumatic arthritis, and other inflammatory disorders which provide more rapid and effective relief rheumatoid inflammation. ${ }^{10}$ Physician surveys have indicated some degree of agreement about which combinations are most effective. Capell's study on 687 patients with rheumatoid found that an inexpensive combination of DMARDs (disease-modifying ant rheumatic drugs) proved more effective than monotherapy in patients with rheumatoid arthritis with a suboptimal response to sulfasalazine. ${ }^{11}$ In addition, several combinations of rheumatoid drugs as initial treatment demonstrated a more rapid improvement in disease activity than those treated with step-up monotherapy in slowing radiographic progression. ${ }^{12,13}$ However, combination therapy has shown more effect than MTX monotherapy and, in fact, a significant increase in the risk of withdrawal of toxicity or lack of efficacy. ${ }^{14,15}$ Generally, combination therapy is well tolerated and associated with no significant increase in the rate of adverse events compared with monotherapy. ${ }^{16}$ The rationale of this study related to the impact of therapies as mono or combined therapies (NSAIDs; Diclofenac sodium $150 \mathrm{mg} /$ day, Meloxicam $15 \mathrm{mg} /$ day, celecoxib 200mg/twice daily: DMARDs; Methotrexate 15mg/wk: Corticosteroid; prednisolone $10-20 \mathrm{mg} /$ day) on the levels of studied biomarkers in rheumatoid arthritis. Therefore, this study was conducted to assess the levels of biomarkers in the rheumatoid arthritis patients treated with a variety of medications to explore the effects of medications on the levels of biomarkers.

\section{Methods}

A cross-sectional study with a comparison group was performed at Hawler Medical University, College of Pharmacy, in cooperation with Rizgari Teaching Hospital, Erbil, Iraq. The patients were recruited from the Rheumatic Center in Rizgari Teaching Hospital from February to July 2018. Eligible patients of both genders, whatever age with a history of rheumatoid arthritis were treated with different modalities of anti-rheumatic drugs as monotherapy, combined therapy, the optimal management of rheumatoid arthritis within 2-7 months after the onset of disease). Patients with a history of liver or kidney diseases, connective tissue disease, terminal illness, and pregnancy were excluded. A total number of 42 patients with rheumatoid arthritis and 44 healthy subjects were included in this study. Information on the whole population was recorded, including their gender and age group. Anthropometric measurements, including the height $(\mathrm{m})$, weight $(\mathrm{kg})$, and the calculated body mass index $\mathrm{kg} / \mathrm{m}^{2}$ were determined. The medications of this study involved non steroidal antiinflammatory drugs, corticosteroids, and 
methotrexate as mono and combined therapies. A venous blood sample was drawn from each patient and placed in an EDTA test tube to determine erythrocyte sedimentation rate and a plain test tube to separate the serum by centrifugation at $3000 \mathrm{rpm}$ for 15 minutes to determine the inflammatory markers. Qualitative determination of C-reactive protein (a cutoff value of $\geq 6 \mathrm{mg} / \mathrm{L}$ ) and rheumatoid factor were determined according to the instructions of the manufacturer. Serum levels of anti-cyclic citrullinated protein, 14-3-3n protein were determined by using enzyme linked immune sorbent assay technology according to the instruction of the manufacturers.

\section{Statistical Analysis}

Statistical analysis was carried out using the statistical package for the social sciences (version 23) computer software in association with Microsoft Excel 2010. The quantitative data were described by mean \pm standard deviation (SD). The statistical significance of the difference between the two groups was assessed using the independent two sample $t$-test for continuous data and Chi-square for categorical data. The $P$ value was considered significant at $\leq 0.05$.

\section{Results}

The age of the studied subjects ranged between ages 25 and 72 . There were no statistically significant differences between group I (case) and group II (comparison) in gender male:female ratio of (9:33 versus $7: 37$ ) accordingly, age (44.47 years versus 44.81 years), respectively, and BMI (26.82 $\mathrm{kg} / \mathrm{m}^{2}$ versus $27.84 \mathrm{~kg} / \mathrm{m}^{2}$ ), respectively (Table 1).

Table 1: Characteristics of the participants.

\begin{tabular}{lccc}
\hline & $\begin{array}{c}\text { Group I } \\
\text { Case } \\
\mathbf{N = 4 2}\end{array}$ & $\begin{array}{c}\text { Group II } \\
\text { Comparison } \\
\mathbf{N = 4 4}\end{array}$ & P value \\
\hline Gender (M:F) & $9(21.42 \%): 33(78.5 \%)$ & $7(15.9 \%): 37(84.1 \%)$ & 0.639 \\
Age (Year) & $44.47 \pm 12.55$ & $44.81 \pm 12.22$ & 0.898 \\
Body Mass Index (Kg/m²) & $26.82 \pm 5.12$ & $27.84 \pm 5.26$ & 0.831 \\
Rheumatic profile & & & \\
Positive C-reactive protein (mg/L) & $30(71.4 \%)$ & $7(15.9 \%)$ & $<0.001$ \\
Positive Rheumatic factor (IU/ml) & $32(72.72 \%)$ & $7(15.9 \%)$ & $<0.001$ \\
Erythrocyte sedimentation rate & $44.78 \pm 26.86$ & $21.841 \pm 5.36$ & $<0.001$ \\
(mm/hr) & & & \\
ACCPA (ng/L) & $0.35 \pm 0.51$ & $0.133 \pm 0.05$ & 0.007 \\
14-3-3n protein (ng/L) & $0.200 \pm 0.42$ & $0.051 \pm 0.009$ & 0.026 \\
\hline
\end{tabular}

The results were expressed as number and mean \pm SD. $P$ value was calculated by using Chi-square test for category data and independent two sample- two tailed t-test for continuous data.

ACCPA: Anti-cyclic citrullinated peptide antibody

Non-significant (N.S) difference $(P>0.05)$ as compared of Group I and Group II.

*Significant difference(S) $(P \leq 0.05)$ as compared of Group I and Group II

** Highly significant difference (H.S) $(P \leq 0.001)$ as compared values of Group I and Group II 
Biochemical rheumatic profile was shown a significantly high frequency of positive reactants toward C-reactive protein and rheumatoid factor among the group I patients compared with group II (Table 1). A highly significant value of erythrocyte sedimentation rate, anticyclic citrullinated protein value, and $14-3-3 \eta$ eta protein were observed in group I compared with normal values of group II (Table 1). The level of early diagnosis traditional biomarkers of inflammation (CRP, RF) that indicate a high titer prediction of inflammatory diagnosis of the rheumatoid disease, differed significantly between the samples of the two groups (Table 2). Patients treated with mono-or-combined therapies expressed significant differences in the serum of ACCPA levels, and non significant change of ESR and 14-3-3n protein values in the patients treated with combined therapy compared with monotherapy (Table 3).

Table 2: Proportions of the samples of groups I \& II by rheumatic factor and C-reactive protein.

\begin{tabular}{|c|c|c|c|c|c|c|}
\hline & \multicolumn{6}{|c|}{ Type } \\
\hline & & \multicolumn{2}{|c|}{$\begin{array}{l}\text { Group I } \\
\text { Case }\end{array}$} & \multicolumn{2}{|c|}{$\begin{array}{c}\text { Group II } \\
\text { Comparison }\end{array}$} & \multirow[t]{2}{*}{$\begin{array}{c}\text { Chi-square } \\
\text { ( } P \text { value })\end{array}$} \\
\hline & & Count & $\%$ & Count & $\%$ & \\
\hline \multirow[t]{2}{*}{$\begin{array}{l}\text { R.F } \\
\text { (IU/ml) }\end{array}$} & - & 10 & 22.7 & 37 & 84.1 & $\begin{array}{c}31.507 \\
(P<0.001)^{\star *}\end{array}$ \\
\hline & + & 32 & 72.72 & 7 & 15.90 & \\
\hline \multirow[t]{2}{*}{$\begin{array}{l}\text { C.R.P } \\
\text { (IU/ml) }\end{array}$} & - & 12 & 27.3 & 37 & 84.1 & $\begin{array}{c}27.021 \\
(P<0.001)^{* *}\end{array}$ \\
\hline & + & 30 & 68.18 & 7 & 15.9 & \\
\hline
\end{tabular}

R.F: Rheumatoid factor

C.R.P: C-reactive protein

Table 3: Comparison between different therapeutic regimens against the rheumatic profile and markers in patients with rheumatoid arthritis.

\begin{tabular}{lccc}
\hline Therapeutic regimen & $\begin{array}{c}\text { ESR } \\
(\mathrm{mm} / \mathrm{h})\end{array}$ & $\begin{array}{c}\text { ACCPA } \\
(\mathrm{ng} / \mathrm{L})\end{array}$ & $\begin{array}{c}14-3-3 \mathrm{n} \text { protein } \\
(\mathrm{ng} / \mathrm{L})\end{array}$ \\
\hline Monotherapy $(\mathrm{n}=13)$ & $45.69 \pm 27.78$ & $0.63 \pm 0.84$ & $0.052 \pm 0.011$ \\
Combined therapy $(\mathrm{n}=\mathbf{2 9})$ & $42.77 \pm 25.66$ & $0.22 \pm 0.18$ & $0.045 \pm 0.005$ \\
$P$ value & 0.749 & 0.015 & 0.324 \\
\hline
\end{tabular}

The results were expressed mean \pm SD. $P$ value was calculated by independent sample t-test ESR: Erythrocyte sedimentation rate

ACCPA: Anti-citrullinated peptide antibody

14-3-3 n protein: $14-3-3$ eta protein 


\section{Discussion}

This study was carried out to determine the effect of mono and combined therapies used in the treatment of rheumatoid arthritis on the blood levels of different inflammatory biomarkers such as RF, CRP, ESR, and ACCPA, and 14-3-3n protein. This was based on the results of previous reports, which showed the importance of these inflammatory biomarkers in the development and progression of rheumatoid arthritis., ${ }^{4,5}$ However, little is known about the effect of the anti-rheumatoid medications both as mono or combined regimen on the activity of novel biomarkers; ACCPA, 14-3-3n protein. The present study, therefore, has investigated the effect of these medications on the selected biomarkers. The current study showed that the female gender was more frequent in rheumatoid arthritis patients (male:female=9:33). The age at which the disease most commonly starts is in women between 40 and 50 years of age, and for men somewhat late. This study is paralleled with that reported by the previous result indicate that rheumatoid arthritis disease is higher in women than in men. ${ }^{17}$ Rheumatoid arthritis can appear at any age, but typically begins between ages 25-70, which was consistent with the findings of the current study. The age of the studied subjects ranged between 25-72 years old. A previous study had illustrated the important role of age in the development of selected autoimmune disease raises whether immune aging is a contributing factor and tolerance defects are part of the degenerative process of the immune system. ${ }^{18} \mathrm{An}$ association between age and rheumatoid arthritis development is unclear, but current research suggests that immunosenescence that occurs with aging can lead to chronic inflammation and immune-mediated tissue damage. ${ }^{19}$ In the current study, there was no statically significant difference in mean age between patients with rheumatoid arthritis (44.47) and healthy comparison (44.81). We also found that there was no statistically significant association in BMl between patients with rheumatoid arthritis $(26.82 \mathrm{~kg} /$ $\mathrm{m}^{2}$ ) and healthy comparison (27.84 $\mathrm{kg} /$ $\left.\mathrm{m}^{2}\right){ }^{20,21}$ The levels of CRP, RF, and ESR as traditional biomarkers help in the diagnosis of rheumatoid arthritis. The current study showed a significantly high frequency of positive reactants toward C-reactive protein, rheumatoid factor, and erythrocyte sedimentation rate among group I patients compared with group II. A previous study detected that the incidence of rheumatoid progression can be predicted by a combination of prognostic factors such as joint involvement, high levels of C-reactive protein, and rheumatoid factor positivity. ${ }^{22}$ Also, pre-study found that the levels of these markers were increased in patients affected by rheumatic arthritis. High concentrations of CRP, RF, and ACCPA in serum are associated with unfavorable outcomes, including persistent disease, joint destruction, and functional disability. ${ }^{23}$ This study determined the novel mediators ACCPA and 14-3-3n protein of autoantibody biomarkers for rheumatoid arthritis that can be detected in early rheumatoid arthritis patients. It indicates the potential effects of adding ACCPA test to reduce the diagnostic gap, improve the diagnostic sensitivity and specificity of rheumatic disease, and give the early potential benefit of the treatment schedule. The therapeutic regimens involved in this study included NSAIDs, corticosteroids, and methotrexate (as monotherapy or combined) to indicate therapy effects on ACCPA, 14-3-3n protein, and ESR levels in rheumatoid patients. As shown in this study, the combined therapy, when compared ACCPA levels, significantly lower than monotherapy at $P=0.015$. Another study concluded that declined ACCPA levels rapidly upon anti-rheumatic therapy and correlated with decreased disease activity in recent-onset rheumatoid arthritis. ${ }^{24} \mathrm{~A}$ study has reported that initial combination therapy consisting of methotrexate plus a biological agent has 
superior efficacy for the induction of remission at one year, and combination therapy has a greater initial effect on achieving clinical remission compared with radiological non-progression. ${ }^{25}$ ESR and 14 $-3-3 \eta$ protein levels were not significantly different between monotherapy and combined biotherapy $(P=0.74$ and 0.324 , respectively). This study indicates ACCPA biomarkers have very good predictive characteristics of detecting inflammation, and they may facilitate the identification of patients with early arthritis who need aggressive treatment. Preceding studies have shown that RF and ACCPA were predictive of progressive disease that suggest effective treatment can prevent radiographic progression, even in patients with risk factors for severe damage. ${ }^{26}$ A study has demonstrated that combination therapy of anti-rheumatic drugs, such as methotrexate (MTX), sulfasalazine, or hydroxylchloroquine, is often more effective than monotherapy in reducing disease activity.27 In addition, another study has concluded that anti-TNFa agents are more efficient in combination with methotrexate than given as monotherapy. ${ }^{28,29}$ A previous research has illustrated that early use of DMARDs (Disease-Modifying Ant rheumatic Drugs) monotherapy with rapid escalation to a combination therapy that may include biologics if disease activity is not controlled and, perhaps, initial combination therapy in patients with severe disease are reasonable therapeutic approaches at this time, although further studies are needed to define what treatment regimens are best for individual patients with early rheumatoid arthritis. ${ }^{30}$ Further studies are required to evaluate the potential effect of specific anti-rheumatic drugs that induced changes more in the inflammatory biomarkers, especially in the $14-3-3 \eta$ protein. The increased availability to treat rheumatoid arthritis provides expanded drug therapy options for patients. Clinical studies show that some of these patients often enroll who have not responded to class of therapeutic regimens of rheumatoid arthritis. The drugs therapy has anti-inflammatory effect on inflammatory biomarkers. These biological markers are very sensitive and specific to the patient's inflammation, indicating that the level of ACCPA had decreased as drug response. Increasing evidence of the importance of ACCPA highlights the need for reliable and better diagnostic and predictive inflammatory biomarkers of rheumatoid arthritis disease and to obtain an effective strategy to control the progression and development of the rheumatoid disease. Also, alteration in the properties of joint cartilage and loss of matrix components is an integral part of cartilage degradation. ACCPA positive patients with rheumatoid arthritis indeed have higher rates of joint damage progression over time. ${ }^{31}$ This study's clinical utility is to find out the new approach for diagnosis and treatment in the early stages of rheumatoid arthritis because this has been valuable in slowing down progression of the disease and reducing high burden medical cost among rheumatoid arthritis patients.

\section{Conclusion}

We concluded from the current study that high levels of ESR, CR, RF (as traditional biomarkers), and 14-3-3n protein, ACCPA (as novel biomarkers) were detected in the patients with rheumatoid arthritis compared with the comparison group. The category number of medicines has played a role in changing of the serum level of the inflammatory markers of ACCPA, which significantly decreased when compared combined with mono biotherapy within the therapeutic regimen.

\section{Competing interests}

The authors declare no competing interests.

\section{References}

1. Majithia V, Geraci SA. Rheumatoid arthritis: diagnosis and management. Am J Med 2007; 120:936-9. 
2. Li C, Mu R, Guo J, Wu X, Tu X, Liu X, et al. Genetic variant in IL33 is associated with susceptibility to rheumatoid arthritis. Arthritis Res Ther 2014; 16(2):1-10.

3. De Almeida PH, Pontes TB, Matheus JP, Muniz LF, De Mota LM. Occupational therapy in rheumatoid arthritis: what rheumatologists need to know? Rev Bras Reumatol 2015; 55(3):27280.

4. Rantapaa-Dahlqvist S, De-Jong BA, Berglin E, Hallmans G, Wadell G, Stenlund H, et al. Antibodies against cyclic citrullinated peptide and IgA rheumatoid factor predict the development of rheumatoid arthritis. Arthritis Rheum 2003; 48(10):2741-9.

5. Shadick NA, Cook NR, Karlson EW, Ridker PM, Maher NE, Manson JE, et al. C-reactive protein in the prediction of rheumatoid arthritis in women. Arch Intern Med 2006; 66(22):2490-4.

6. Gavrilă BI, Ciofu C, Stoica V. Biomarkers in rheumatoid arthritis, what is new? J Med Life 2016; 9(2):140-8.

7. Saag KG, Teng GG, Patkar NM. American College of Rheumatology 2008 recommendations for the use of nonbiologic and biologic disease-modifying anti-rheumatic drugs in rheumatoid arthritis. Arthritis Rheum 2008; 59(6):762-84.

8. Rindfleisch JA, Muller D. Diagnosis and management of rheumatoid arthritis. Am Fam Physician 2005; 72(6):1037-47.

9. Wasserman AM. Diagnosis and management of rheumatoid arthritis. Am Fam Physician 2011; 84(11):1245-52.

10. Crofford LJ. Use of NSAIDs in treating patients with arthritis.Arthritis Res Ther 2013; 15(3):2-10.

11. Capell HA, Madhok R, Porter DR, Munro RA, Mclnnesl B, Hunter JA, et al. Combination therapy with sulfasalazine and methotrexate is more effective than either drug alone in patients with rheumatoid arthritis with a suboptimal response to sulfasalazine: results from the double -blind placebo-controlled MASCOT study. Ann Rheum Dis 2007; 66(2):235-41.

12. Steunebrink ML, Versteeg LG, Vonkeman HE, Ten Klooste PM, Hoekstra M, van de Laar MA. Radiographic progression in early rheumatoid arthritis patients following initial combination versus step-up treat-totarget therapy in daily clinical practice: results from the DREAM registry. BMC Rheumatol 2018; 2(1):2-10.

13. Combe B, Lula S, Boone C, Durez P. Effects of biologic disease-modifying anti-rheumatic drugs on the radiographic progression of rheumatoid arthritis: a systematic literature review. Clin Exp Rheumatol 2018; 36(4):658-67.

14. Katchamart W, Trudeau J, Phumethum V, Bombardier C. Efficacy and toxicity of methotrexate (MTX) monotherapy versus MTX combination therapy with non-biological disease-modifying anti-rheumatic drugs in rheumatoid arthritis: a systematic review and meta-analysis. Ann Rheum Dis 2009; 68(7):1105 -12 .

15. Boshra MS, Ahmed AS, Salem HF, Abd El Hamid MN. Safety and efficacy of methotrexate monotherapy vs methotrexate plus leflunomide combination therapy in early active rheumatoid arthritis patients. Medicine Science 2016; 5(1):117-33.

16. Dale J, Alcorn N, Capell H, Madhok R. Combination therapy for rheumatoid arthritis: methotrexate and sulfasalazine together or with other DMARDs. Nat Clin Pract Rheumatol 2007; 3(8):450-8.

17. Sokka T, Toloza S, Cutolo M, Kautiainen $H$, Makinen $H$, Gogus $F$, et al. Women, men, and rheumatoid arthritis: analyses of disease activity, disease characteristics, and treatments in the QUEST-RA Study. Arthritis Res Ther 2009; 11(1):1-12.

18. Pawłowska J, Smolen' ska Z, Daca A, Witkowski JM, Bryl E. Older age of rheumatoid arthritis onset is associated with higher activation status of peripheral blood CD4+ T cells and disease activity. Clin Exp Immunol 2010; 163:157-64.

19. Weyand CM, Yang Z, Goronzy JJ. T-cell aging in rheumatoid arthritis. Curr Opin Rheumatol 2014; 26:93-100.

20. Sparks JA, Chiao Chang Sh, Nguyen U, Barbhaiya M, Tedeschi SK, Lu B, et al. Weight change during the early rheumatoid arthritis period and risk of subsequent mortality in women with rheumatoid arthritis and matched comparators. Arthritis Rheumatol 2018; 70(1):18-29.

21. England BR, Baker JF, Sayles $H$, Michaud K, Caplan L, Davis LA, et al. Body mass index, weight loss, and cause-specific mortality in rheumatoid arthritis. Arthritis Care Res 2018; 70(1):11-8.

22. Scott DL. Prognostic factors in early rheumatoid arthritis. Rheumatology 2000; 39(1):24-9.

23. Carvalho CD, Andrade LE, Keusseyan SP, Rangel JL, Ferreira-Strixino J, Martin AA, et al. Study of advanced rheumatoid arthritis. Revista Brasileira de Engenharia Biomédica 2014; 30(1):54-63.

24. Kastbom A, Roos Ljungberg K, Ziegelasch M, Wetterö J, Skogh T, Martinsson K. Changes in anti-citrullinated protein antibody isotype levels in relation to disease activity and response to treatment in early rheumatoid arthritis. Clin Explmmunol 2018; 194(3):391-9.

25. Kuriya B, Arkema EV, Bykerk VP, Keystone EC. Efficacy of initial methotrexate monotherapy versus combination therapy with a biological agent in early rheumatoid arthritis: a meta-analysis of clinical and radiographic remission. Ann Rheum Dis 2010; 69:1298-304.

26. De Vries-Bouwstra JK, Goekoop-Ruiterman YP, Verpoort KN, Schreuder GM, Ewals JA, 
Terwiel JP, et al. Progression of joint damage in earlyrheumatoid arthritis: Association with HLADRB1, rheumatoid factor, and anti-citrullinated protein antibodies in relation to different treatment strategies. Arthritis \& Rheumatism 2008; 58(5):1293-8.

27. Gibofsky A. Combination Therapy for Rheumatoid Arthritis in the Era of Biologicals. HSS J 2006; 2(1):30-41.

28. Strangfeld A, Hierse F, Kekow J, Vonhinueber U, Tony H-P, DockhornR, et al. A comparative effectiveness of tumour necrosis factor a inhibitors in combination with either methotrexate or leflunomide. Ann Rheum Dis 2009; 68:1856-62.

29. Inui K, Koike T. Combination therapy with biologic agents in rheumatic diseases: current and future prospects. Ther Adv Musculoskelet Dis 2016; 8(5):192-202.

30. Demoruelle K, Deane K. Treatment Strategies in Early Rheumatoid Arthritis and Prevention of Rheumatoid Arthritis. Curr Rheumatol Rep 2012; 14(5):472-80.

31. Van den broek $M$, Dirven $L$, Klarenbeek NB, Molenaar $\mathrm{TH}$, Han $\mathrm{KH}$, Kerstens $\mathrm{PJ}$, et al. The association of treatment response and joint damage with ACPA-status in recent-onset RA: a subanalysis of the 8-year follow-up of the BeSt study. Ann Rheum Dis 2012; 71:245-8. 